\title{
aniki
}

Revista Portuguesa da Imagem em Movimento

Portuguese Journal of the Moving Image

\section{Tempo, magnitude e o mito do cinema moderno ${ }^{1}$ Lúcia Nagib $^{2}$}

\author{
O Tejo é mais belo que o rio que corre pela minha aldeia, \\ Mas o Tejo não é mais belo que o rio que corre pela minha aldeia \\ Porque o Tejo não é o rio que corre pela minha aldeia'. \\ Alberto Caeiro (Fernando Pessoa), O Guardador de Rebanhos \\ Lampião era grande, mas também ficava pequeno. \\ Dadá, em Deus e o diabo na Terra do Sol
}

Vista de perto aumentava em favor do coração o que perdia em quilate dos olhos. Era mulher para ver-se, mas era mais para amar-se. Comentário off em Mistérios de Lisboa

Neste texto, irei abordar três filmes ambientados em Portugal, cujas locações oferecem uma visão privilegiada da função do tempo e da magnitude no cinema, os quais, por sua vez, nos permitem reavaliar as categorias de clássico, moderno e pós-moderno aplicadas a esse meio. Trata-se de $O$ estado das coisas (Der Stand der Dinge, Wim Wenders, 1982), Terra estrangeira (Walter Salles and Daniela Thomas, 1995) e Mistérios de Lisboa (Raúl Ruiz, 2010). Neles, a cidade se compõe de círculos viciosos, espelhos, réplicas e mise-en-abyme que interrompem o movimento vertiginoso característico da cidade modernista do cinema dos anos 20. Curiosamente, é também o lugar em que a assim chamada estética pós-moderna finalmente encontra abrigo em contos auto-irônicos que expõem as insuficiências dos mecanismos narrativos no cinema. Para compensá-las, recorre-se a procedimentos de intermídia, tais como fotografias de Polaroid em $O$ estado das coisas ou um teatro de papelão em Mistérios de Lisboa, que transformam uma realidade incomensurável em miniaturas fáceis de enquadrar e manipular. O real assim diminuído, no entanto, se revela um simulacro decepcionante, um ersatz da memória que evidencia o caráter ilusório da teleologia cosmopolita.

Em minha abordagem, começarei por examinar a gênese interligada e transnacional desses filmes que resultou em três visões correlatas mas muito diversas do fim da história e da narrativa, típico da estética pós-moderna. A seguir, irei considerar o miniaturismo intermedial como uma tentativa de congelar o tempo no interior do movimento, uma equação que inevitavelmente nos remete ao binário

\footnotetext{
${ }^{1}$ Este texto foi originalmente escrito para o livro World Cinema: as novas cartografias do cinema mundial (organização de Stephanie Dennison). Campinas: Papirus, 2014.

${ }^{2}$ University of Reading (UK).
} 
deleuziano tempo-movimento, que também irei revisitar com o fim de distingui-lo da oposição entre cinema clássico e moderno. Por fim, irei propor a stasis reflexiva e a inversão de escala como denominadores comuns entre todos os projetos ditos modernos, que por esta razão, segundo creio, são mais confiáveis que a modernidade enquanto indicadores de valores artísticos e políticos.

\section{Interlúdio cinefílico}

Costuma-se considerar típico do cinema pós-moderno o recurso à cinefilia como um modo de compensar a estagnação criativa. De fato, a conexão portuguesa que focalizo aqui teve origem num período dominado por uma onda revisionista no cinema. O cinema português é famoso por sua originalidade e adesão intransigente e precoce ao que se convencionou chamar de slow cinema, ou 'cinema lento'. A cinefilia sentou fortes raízes em Portugal, cuja tradição de privilegiar qualidade sobre quantidade tem gerado alguns gigantes do cinema mundial, como o cineasta mais idoso do mundo, Manoel de Oliveira, ainda ativo aos 104 anos de idade; o cineasta multidisciplinar e autoperformático João César Monteiro; o diretor predileto de Rancière, Pedro Costa; e o mais recente fenômeno do cinema autoral, Miguel Gomes. Essa combinação de liberdade criativa, cinefilia e cinema lento constituiu sem dúvida a principal atração para os quatro diretores enfocados aqui, Raúl Ruiz, Wim Wenders, Walter Salles e Daniela Thomas. Embora provenientes de gerações, lugares e culturas inteiramente distintos, todos escolheram filmar em Portugal em momentos decisivos de sua carreira como um porto seguro para recalibrar sua pulsão criativa. Essa espécie de 'interlúdio português' lhes proporcionou a oportunidade de tomar distância de situações difíceis em seus países de origem ou de residência para se dedicarem calmamente à experimentação.

O resultado foram filmes marcados pela angústia (ou constatação irônica) da derrota e da morte: a morte do cinema, em Wenders; o fim do império colonial europeu, em Ruiz; e o fracasso da reconciliação pós-colonial, em Salles e Thomas. Foi Ruiz quem, em 1981, com $O$ território, um filme barato e despretensioso, inaugurou a moda do interlúdio português, que a seguir contagiou seus pares numa reação em cadeia alimentada pela cinefilia transnacional. Ruiz, infelizmente falecido há pouco, era um artista chileno exilado na França desde meados dos anos 70, para quem Portugal constituiu uma fuga dentro de uma fuga, possibilitando-lhe extravasar sua criatividade frenética em filmes radicalmente independentes.

No mesmo período, no final dos anos 70, dando início a uma tendência mundial fortemente recessiva, Hollywood foi tomada por uma onda de remakes e continuações destinada a reciclar tanto sua própria produção quanto clássicos estrangeiros. Na Europa e outras regiões do mundo, o fim dos novos cinemas revolucionários força- 
ram os respectivos cineastas a olhar para trás em busca de matériaprima. Wim Wenders, o garoto prodígio do Novo Cinema Alemão dos anos 60 e 70, foi um dos primeiros a embarcar nessa onda. Em 1978, a convite de Francis Ford Coppola, ele abandonou a cena estagnada de sua pátria alemã rumo aos Estados Unidos, com o intuito de participar do movimento de reciclagem de gêneros canônicos Hollywoodianos que também refletia sobre o declínio criativo da sua própria geração. O resultado foi Hammett, uma malfadada homenagem ao filme noir americano, cuja produção, pontuada de desastres, se estendeu por mais de quatro anos. Nesse meio tempo, porém, Wenders conseguiu rodar dois filmes independentes, destinados a promover um acerto de contas com Coppola e Hollywood: Reverse Angle (1982) e o filme em questão aqui, O estado das coisas.

Diz a lenda que, em uma de suas viagens entre a Europa e os Estados Unidos, onde Hammett estava parado por desavenças com Coppola, Wenders fez uma escala em Sintra, com o intuito de doar sobras de filme a Raúl Ruiz, cujo filme $O$ território também estava parado, mas por falta de fundos. Wenders teria gostado tanto do copião e da atmosfera descontraída do filme de Ruiz, que impôs como condição para sua boa ação que todo o elenco e a equipe de O território permanecessem em Portugal para trabalhar num filme seu, que começou a escrever naquele mesmo instante. Assim $O$ estado das coisas nasceu como uma espécie de continuação, ou metacomentário, de O território. O título do filme, no entanto, já era parte do repertório de Wenders desde 1972, quando planejara rodar, em suas palavras, um "filme inteiramente fenomenológico... algo puramente descritivo" (Wenders 2001, 197), frase que confirma sua antiga obsessão com a ideia de estagnação e movimento em falso, expressa no título de um de seus filmes iniciais, Falsche Bewegung (1975) (cf. Schütte in Wenders 2001, 197).

Em O estado das coisas, signos de stasis se multiplicam em mise-en-abyme, num branco e preto nostálgico a cargo do famoso cameraman da nouvelle vague, Henri Alekan. O filme começa com um remake do filme de Roger Corman $O$ dia em que o mundo acabou (The Day the World Ended, 1959), sob o título de Os sobreviventes (The Survivors) - vale lembrar que Corman é co-produtor de O território e também faz uma ponta em $O$ estado das coisas. A seguir o foco se dirige para o elenco e a equipe envolvidos na filmagem desse remake, interrompida por falta de filme virgem tal como acontecera na realidade com $O$ território. $\mathrm{O}$ resto do filme gira em torno da espera interminável dos personagens pela ajuda financeira do produtor americano desaparecido, chamado Gordon numa alusão velada ao Godot de Beckett. Atores e técnicos matam o tempo com atividades solitárias no hotel em Sintra, uma ruína parcialmente submersa no mar, ou com passeios em Sintra e Lisboa. Enquanto isso, o diretor, Fritz Munro - assim chamado em homenagem tanto a Fritz Lang quando a Friedrich Wilhelm Murnau — viaja de volta a Hollywood à procura 
de Gordon, onde ambos afinal se encontram e acabam sendo assassinados.

Quanto a Terra estrangeira, trata-se de uma co-produção brasileira e portuguesa, cujo produtor executivo, António da Cunha Telles, também financiou vários filmes de Ruiz. Foi no entanto Wenders quem ofereceu a saída ideal para Salles e Thomas, no período fatídico do governo Collor que causou a interrupção da produção de filmes no Brasil no início dos anos 1990. Walter Salles é admirador confesso de Wenders (Araujo 2002, 419), fato este evidenciado pelos viajantes sem destino que povoam seus filmes, desde os primeiros até sua recente adaptação de On the Road de Jack Kerouac, todos reminiscentes dos personagens dos filmes de Wenders dos anos 70, como No decorrer do tempo (Im Lauf der Zeit, 1976) e Alice nas cidades (Alice in den Städten, 1974). Em Terra estrangeira, a opção por preto e branco, embora ligada a questões financeiras, não é menos tributária da preferência de Wenders por esse estilo em seus filmes iniciais. E, naturalmente, Terra estrangeira se irmana a $O$ estado das coisas pelas locações portuguesas, e não é mera coincidência que Wenders se encontrasse novamente em Portugal, filmando Lisbon Story, no mesmo ano de 1994 em que Salles, Thomas e sua equipe estavam por lá fazendo Terra estrangeira (cf. comentário de Thomas a esse respeito em Araujo 2002, 485). O filme conta a história de imigrantes brasileiros em Lisboa vivendo de bicos e trambiques, como tráfico de drogas e pedras preciosas. Lá encontram seus parceiros da África póscolonial com quem compartilham a degradante situação de subemprego e ilegalidade, enquanto Portugal em si é retratado como um pária na periferia da Europa. Embora sua estrutura narrativa seja a mais convencional dos três filmes em foco aqui, Terra estrangeira também compartilha da tendência pós-moderna graças à profusão de citações de outros filmes - Welles, Huston, Herzog, Godard - e fontes literárias - Pessoa, Goethe e Shakespeare. Ademais, confirma a duradoura atração de Portugal sobre o cinema de autor que culmina em 2010 com o melhor filme entre mais de uma centena dirigida por Raúl Ruiz, Mistérios de Lisboa.

Conferindo um fecho magnífico à corrente cinefílica que o próprio Ruiz inaugurara duas décadas antes, Mistérios de Lisboa é uma obra monumental de mais de quatro horas de duração enquanto filme de longa metragem e pelo menos seis horas no formato original de série televisiva. Mise-en-abyme é a regra nesta adaptação magistral realizada por Carlos Saboga do romance do escritor romântico português Camilo Castelo Branco em três volumes, contendo um emaranhado de histórias que se espraiam ao longo de várias gerações, com a típica elasticidade do gênero folhetinesco. Inteiramente rodado em Portugal e em português, o filme versa sobre a decadência moral de uma burguesia parasitária, vivendo às custas da pilhagem colonial, e libertinos arrependidos disfarçados de clérigos misteriosos. Com sua narrativa polifônica e virtuosismo intermedial, Mistérios 
de Lisboa oferece, ao lado dos outros dois filmes, a plataforma ideal para a revisão e superação do limitado modelo tripartite que divide o cinema em clássico, moderno e pós-moderno.

\section{Stasis reflexiva e inversão de escala}

Proponho agora considerar a caracterização de Portugal através de Lisboa e Sintra nos três filmes em questão. Neles, a cidade está longe de ser a combinação de multidões, máquinas e movimento incessante característicos do cinema urbano modernista, como se vê em Berlim, sinfonia da metrópole (Berlin: Die Sinfonie der Großtadt, Walter Rutmann, 1927), O homem da câmera (Dziga Vertov, 1929) ou Metrópolis (Fritz Lang, 1927). Ao contrário, Lisboa e Sintra parecem ter sido escolhidas precisamente por possibilitarem a representação da cidade por meio de uma iconografia de estagnação, desertificação e ruína, em vez de dinamismo industrial.

O cenário principal de $O$ estado das coisas é um hotel monumental e deserto, semi-erodido pelo mar, na realidade o Hotel Arribas, na orla de Sintra. Embora tenha sido recentemente restaurado e devolvido à sua glória original, no momento da filmagem os fundos do edifício, contendo uma magnífica piscina de 100 metros, encontravam-se parcialmente submersos no Atlântico. Ao se deparar com esta extravagante ruína em Sintra, Wenders teria imediatamente decidido rodar seu próximo filme ali (Boujout 1986: 99). Fruto da arquitetura modernista típica dos anos 1960, o Hotel Arribas introduz um tema que atravessa o filme como um todo: a natureza oximorônica do progresso capitalista, com sua indústria turística e de entretenimento, cuja degradação é constitutiva da novidade que alardeia - fato confirmado de forma alarmante pelos aparelhos eletrônicos, inclusive um dos primeiros computadores Apple, exibido no filme como tecnologia de última geração, mas que hoje nos parece sucata. Apresentados como passatempos solitários, os gadgets e atividades artísticas do filme congelam o tempo em motivos estáticos e repetitivos de fotografias, pinturas, desenhos, mensagens escritas e gravações sonoras.

Significativamente, a reprodução do real através de gadgets e atividades artísticas é o modo que os personagens encontram para se reconciliar com uma realidade avassaladora que eles não conseguem compreender ou dominar. Numa cena que é quase literalmente reproduzida em Terra estrangeira, a namorada de Fritz, Kate, cai em prantos ao olhar para a paisagem marítima monumental cujos contornos ela não consegue desenhar no papel. Enquanto isso, um casal dentre o elenco ocioso enquadra e fotografa a mesma paisagem, reduzindo-a a miniatura e inócuo simulacro.

Manipulação de escala e proporção é uma propriedade fundamental da fotografia e do cinema, sendo o close-up a mais radical distorção do real que ambos possibilitam. Mary Ann Doane relaciona 
o efeito de tais distorções sobre o espectador diretamente com o crescimento capitalista, na medida em que o sujeito se define como "epistemologicamente inadequado" e "incapaz de jamais mapear ou realmente compreender a totalidade das forças sociais que determinam sua posição" (2009, 63). Diz Doane: "Embora a miniatura pareça completamente inteligível e assimilável, o objeto gigante... excede a compreensão do espectador e evidencia os limites do conhecimento parcial" (63). Em O estado das coisas, o conflito dos personagens auto-reflexivos diante da impossibilidade de reproduzir o real em sua totalidade avassaladora os conecta diretamente à natureza descartável da fotografia como produto industrial. A impossível magnitude do real faz então com que os personagens (constituídos do elenco e da equipe de um filme dentro de um filme) percebam sua diminuta importância dentro de um cenário gigantesco, fato este ilustrado pela minúscula Romiseta estacionada na portentosa ruína dos fundos do hotel. Os enquadramentos estáticos e descritivos utilizados para produzir tal efeito constantemente realçam a paralisia fotográfica inerente ao filme de celuloide e enfatizam a ansiedade da morte do cinema que reina no nível temático do filme, corroborada pelas inúmeras imagens de cinemas em ruínas nas ruas de Sintra, Lisboa e, no final do filme, Los Angeles.

Num nível metafórico semelhante, a cidade é repetidamente comparada a um navio a pique, à medida que as ondas invadem os fundos do hotel. Um dos personagens aponta para um globo terrestre de plástico e comenta: "Lisboa fica realmente bem na beirada, na ponta mais ocidental da Europa, de fato a água chega até a minha janela". A metáfora do naufrágio reaparece constantemente nos diálogos dos personagens, por exemplo, quando Fritz lê em voz alta, para si mesmo, no livro The Searchers, sobre "o sentimento terrível de inevitável fracasso que o dominava toda vez que encontrava aquele navio".

A ideia de ruína e fracasso que impedem a progressão histórica está também no cerne de Terra estrangeira, um filme ainda mais fortemente dominado pelo motivo do naufrágio que reaparece tanto na iconografia como na letra da canção intradiegética entoada pela protagonista Alex. Segundo Salles, na origem do filme estão as fotografias de um navio encalhado na costa do Cabo Verde tiradas pelo fotógrafo francês Jean-Pierre Favreau (Thomas, Bernstein e Salles 1996, 5). Salles levou equipe e elenco ao Cabo Verde para filmar o casal protagonista com esse navio ao fundo, editando a seguir a cena como se fosse em Portugal, em combinação com as majestosas imagens de mar nos arredores de Sintra e do rio Tejo em Lisboa. Aqui, em lugar do capitalismo arquitetônico e tecnológico, o foco recai sobre o fracasso do projeto colonial, num conto de imigrantes e populações diaspóricas cujas desventuras remetem à era dos grandes descobrimentos. A mesma ideia perpassa os diálogos, os quais conectam o motivo do naufrágio à desilusão com o projeto 
urbano, por exemplo, neste comentário do livreiro Pedro sobre Lisboa: "Isto aqui não é sítio para encontrar ninguém. Isto é uma terra de gente que partiu para o mar. É o lugar ideal para perder alguém ou para perder-se de si próprio.”

Se neste filme a ideia de fracasso monumental se deve a Wenders, a outra referência cinefílica fundamental é Glauber Rocha e a iconografia do mar em Deus e o diabo na terra do sol (1964) e, mais especificamente, Terra em transe (1967), este último um delirante compêndio dos fracassos históricos brasileiros sobre o pano de fundo da mitologia do descobrimento. Em Terra estrangeira, monumentalidade incompreensível e inversão de escala desempenham um papel-chave no confronto entre colonizador e colonizado, como na famosa cena em que os personagens brasileiros se dão conta das dimensões irrisórias de seu gigantesco território de origem, quando visto pela perspectiva do colonizador. Paco e Alex, o casal protagonista, se encontram em Cabo Espichel (a mesma locação do filme de Wenders), definido no filme como o ponto mais extremo do oeste da Europa, ${ }^{3}$ sentados à beira de um precipício diante do qual se estende o vasto mar. Este, por um momento, ocupa todo o quadro, e então a câmera recua para tomar Alex e Paco de costas, no topo da falésia, com o mar a sua frente. Trocam então o seguinte diálogo auto-irônico:

Alex:

- Você não tem nem idéia de onde você está, né? Isso aqui é a ponta da Europa. (abrindo os braços) Isso aqui é o fim! Coragem, né? Cruzar esse mar há 500 anos atrás... É que eles achavam que o paraíso estava ali, ó. (aponta para o horizonte, à esquerda) Coitados dos portugueses... acabaram descobrindo o Brasil.

Paco ri. Alex permanece séria.

Alex:

- Tá rindo de quê?

Por fim, em Mistérios de Lisboa, a cidade do título parece já ter sido engolida e lançada no esquecimento, pois permanece ausente do restrito campo visual dos personagens provincianos do século XIX, que nada percebem além das estreitas molduras de espelhos e janelas dos conventos, casas e carruagens onde se encontram. Evidentemente, tal recurso pode ser visto como típico de filmes de estúdio e séries de TV, que este filme também é na origem, nos quais o uso recorrente de close-ups extremos trai a intenção de se evitar a construção de cenários dispendiosos. Enquanto possível adepto desse truque, o estilo narrativo de Mistérios de Lisboa poderia ser visto como clássico ou comercial. No entanto, o modo explícito como esse recurso é empregado de modo a chamar a atenção do espectador para sua

\footnotetext{
${ }^{3}$ Na realidade, o ponto mais extremo do oeste de Portugal (e portanto da Europa) é o Cabo da Roca, próximo a Espichel.
} 
artificialidade e chamar a atenção à cidade por sua ausência remete à auto-reflexividade normalmente atribuída ao cinema moderno.

Por outro lado, a superposição de histórias semelhantes através de gerações, sugerindo simultaneidade em vez de progresso histórico, põe em dúvida a teleologia moderna. As constantes interferências intermediais enfatizam a ideia de stasis e congelam os episódios históricos em pinturas, motivos pictóricos de azulejos portugueses e, em particular, em cenas representadas com o auxílio de um teatro de papelão em miniatura, que Pedro ganhou de sua mãe quando a encontrou pela primeira vez aos 14 anos. A razão pela qual Pedro foi criado num convento e mantido separado da mãe por tanto tempo é apenas um dos muitos mistérios que ele tem de enfrentar, numa trama complicada que desvela sucessivamente as várias identidades do Padre Dinis, responsável pela educação do menino. Uma cena em particular resume a concepção do filme como um todo. Pedro encontra-se primeiramente na posição de espectador de um filme que está vendo e ouvindo através de uma janela; no lado de fora, Padre Dinis, acompanhado do personagem de Dona Antónia, pede à mãe de Pedro que perdoe seu marido tirânico que se encontra à beira da morte em Santarém. Pedro é radicalmente contra esse plano, porque suspeita, com razão, que isso irá separá-lo mais uma vez de sua mãe. A cena é então substituída pelos personagens de um teatro de papelão em miniatura representando sua mãe, Padre Dinis e Dona Antónia, que Pedro derruba um a um com meros piparotes. Esta passagem auto-reflexiva, ao mesmo tempo que reduz o cinema a sua realidade de ficção e reprodução mecânica, enfatiza a função da inversão de escala como artifício que propicia a participação do espectador.

A dialética da escala no cinema foi estudada, entre outros, por Deleuze, que definiu a ênfase nas formas grandes e pequenas como típica do cinema de ação e montagem, dando os exemplos de Eisenstein, quanto à forma grande, e Chaplin, quanto à forma pequena (Deleuze 2005a, 145ff.). Nas três cenas descritas aqui, no entanto, a inversão de escala invariavelmente resulta, não em ação, mas em stasis reflexiva, na medida em que espectadores perplexos na diegese provocam a paralisia da ação. Desse modo, a figura da inversão de escala estaria em consonância com a ideia deleuziana da imagemtempo e do personagem observador ou voyant, pondo em dúvida, ao mesmo tempo, a classificação desses recursos como clássicos ou modernos.

\section{Ruínas modernas e pós-modernas}

A representação da cidade através de ruínas, desertificação e estagnação, em lugar do tumulto e do movimento perpétuo inerente à experiência do modernismo urbano, tal como encontrada em $O$ estado das coisas e Terra estrangeira, bem como a ausência de motivos 
visuais urbanos, no caso de Mistérios de Lisboa, costumam ser vistos como típicos da cidade pós-moderna. Com efeito, esses filmes parecem seguir à letra a receita pós-moderna que combina nostalgia, citação e auto-desconstrução narrativa. Como diz Dudley Andrew:

Antes da Segunda Guerra Mundial, o modernismo cinematográfico se alinhava ao de Joyce, Döblin e Dos Passos no modo de representação visual da cidade de 'forma sinfônica'; já para os escritores e cineastas pósmodernos a cidade é invisível, discordante e fundamentalmente irrepresentável. Simultaneidade temporal e equivalência espacial contradizem o espaço-tempo do filme, pois nas cidades atuais simultaneidade pode significar que os personagens se encontram em lugar nenhum ou em todos os lugares ao mesmo tempo. (Andrew 2010, 37)

No que tange a associação da experiência urbana com a ideia de fracasso, no entanto, as cidades pós-modernas diferem pouco daquilo que normalmente se entende como cidade 'moderna', já a partir da centralidade das imagens de guerra, catástrofe e ruína no próprio conceito de modernidade. Basta citar o memorável aforismo de Walter Benjamin sobre o 'Angelus Novus', de Paul Klee, que define a modernidade como um anjo que olha aterrorizado para os detritos do passado, enquanto o vento tempestuoso do progresso o impele para o futuro (Benjamin 1999, 249). Cabe lembrar que este anjo viria a ganhar dupla representação num filme posterior de Wenders, Asas do desejo (Der Himmel über Berlin, 1987), ambientado numa Berlim fraturada e marcada pela guerra.

A importância política das ruínas no projeto cinematográfico moderno deriva do fato de que, ao chamar a atenção para as catástrofes do passado, elas dão lugar à stasis auto-reflexiva que, por sua vez, abrem espaço para a participação do espectador. Hell e Schönle sintetizam esse fenômeno com precisão, nos seguintes termos:

Em sua ambivalência e amorfia, a ruína funciona como um tropo único, flexível e produtivo da auto-consciência da modernidade. Com efeito, trata-se de figura-chave da reflexividade moderna, por combinar justamente a vacuidade e a perda que estão na base constitutiva da identidade moderna. É a reflexividade de uma cultura que interroga seu próprio devir. (2010, 6-7)

Filme fundamental dentro da cadeia cinefílica descrita acima, Mistérios de Lisboa é uma apologia das ruínas imaginárias de Portugal, como deixa claro o protagonista, Padre Dinis, no romance que lhe deu origem, nos seguintes termos apocalípticos:

Tudo vai levar um tombo em Portugal. Vem perto o dia em que a vida aqui para muitos será aborrecida e enojada. Os princípios desorganizam-se, a guerra civil não se acomoda com um pequeno tributo de sangue, não há vencidos nem vencedores; a anarquia, depois da guerra, entrará no governo, qualquer que ele seja, e os alicerces do novo edifício serão cadáveres e as ruínas de muitas fortunas. Felizes os que podem ver de longe a pátria nas garras do abutre. (Castelo Branco 2010, 160)

Como se sabe, cenários urbanos em ruínas, em particular os de filmes neo-realistas como Alemanha ano zero (Germania anno zero, Roberto Rossellini, 1947), constituem, para Bazin, o cerne realista da 
modernidade cinematográfica. Do mesmo modo, para Deleuze, o fim da Segunda Guerra Mundial marca o início do cinema moderno. Em trechos que poderiam ser aplicados diretamente aos filmes analisados aqui, Deleuze descreve os espaços urbanos do pós-guerra como "espaços quaisquer," feitos de "cidades demolidas..., terrenos baldios, favelas... vastas áreas desocupadas, galpões, depósitos, montes de ferro velho e sucata" (Deleuze 2005a, 169), a maioria dos quais pode ser encontrada no filme-catástrofe de ficção científica Os sobreviventes, o filme dentro do filme de $O$ estado das coisas. A magnitude da guerra, para Deleuze, faz com que a imagem-tempo, típica da modernidade, interfira e interrompa a imagem-ação que ele atribui ao cinema clássico hollywoodiano e ao cinema de montagem em geral, gerando personagens observadores ou voyants em lugar de agentes, num mundo que ultrapassa sua compreensão.

Dada a recorrência da guerra na história da humanidade, no entanto, haveria escopo para se investigar a combinação de ruínas e modernidade antes da Segunda Guerra Mundial. De fato, Johannes von Moltke $(2010,396)$ encontra ruínas na própria origem do cinema, por exemplo, no filme dos irmãos Lumière entitulado Demolição de um muro (Démolition d'un mur, 1895), que mostra a destruição de um muro e sua imediata reconstrução obtida com o simples truque de projetar o filme de trás para frente. A isto adiciona-se o fato de que o cinema não apenas se relaciona com a modernidade mas é resultado dela. Como explica Singer, o cinema surgiu "no ambiente sensório da modernidade" como resultado das "tecnologias de espaço e tempo do final do século XIX e suas interações com elementos adjacentes na nova cultura visual do capitalismo avançado" $(2001,102)$. Este fato inegável, no entanto, não impediu Bazin de desenvolver um conceito de cinema moderno no pós-guerra, baseado no realismo fenomenológico, que não apenas desconsidera a natureza moderna do cinema, mas exclui da modernidade as próprias vanguardas modernistas dos anos 20, e mesmo Eisenstein, por praticarem a montagem. Deleuze, a seguir, consolidou esse modelo ao rebatizá-lo de imagem-tempo versus imagem-movimento. Muitas outras apropriações do projeto moderno surgiram no rastro dessas abordagens fundadoras, propondo-se a defender certos filmes contra outros, sendo Hollywood o costumeiro vilão. Os beneficiários são os novos cinemas dos anos 60 e 70 (Orr 2000, 7), bem como fenômenos mais recentes, definidos como modernos ou 'neo-modernos' em oposição à norma clássica ou conservadora.

Por outro lado, o teórico pioneiro da condição pós-moderna, Jean-François Lyotard, data a pós-modernidade do nascimento de uma Europa reconstruída, isto é, "pelo menos do final dos anos 50, que na Europa marca o término da reconstrução" (1986, 3). Tal entendimento decerto contradiz a maioria das abordagens do projeto moderno descritas aqui, a começar pela periodização de Bazin e Deleuze, que atribui o rótulo de moderno a uma variedade de produções 
chegando até seu momento presente. Tanto Bazin quanto Deleuze defendem a modernidade com base na novidade - portanto ímpeto progressista - inerente ao sentido original do termo 'moderno', ideia esta que também ecoa em tempos mais recentes na defesa do moderno empreendida por Habermas em termos de uma revolta "contra as funções normalizadoras da tradição' e 'contra tudo que é normativo” (Habermas e Ben-Habib 1981, 5). Em seu debate público com Lyotard, Habermas recusou-se a aceitar o fim do projeto moderno e de sua prerrogativa política progressista, desdenhando a descrição do colega francês da queda em desgraça, na era pós-moderna, do saber científico e racional (1986, xxiv).

No que concerne o cinema, no entanto, Deleuze complica a equação ao atribuir um caráter progressista à imagem-movimento, isto é, ao cinema clássico, em vez do moderno, nos seguintes termos:

O tempo como curso decorre da imagem-movimento, ou dos planos sucessivos... Mas no cinema moderno, ao contrário, a imagem-tempo já não é empírica, nem metafísica, é 'transcendental' no sentido que Kant dá a esta palavra: o tempo sai dos eixos e se apresenta em estado puro. (2005b, 322)

Tal entendimento ressoa de forma notável com os fenômenos de stasis temporal e estagnação urbana observados nos filmes em questão aqui, tornando-os sujeitos em igual medida à caraterização de modernos e pós-modernos, e pondo em questão a utilidade de tal critério. Como Rancière observa:

Se há uma questão política na arte contemporânea, ela não deve ser compreendida em termos de uma oposição entre moderno e pós-moderno. Deve ser compreendida através da análise das metamorfoses de um 'terceiro' político, uma política fundada no jogo de trocas e deslocamentos entre o mundo da arte e da não-arte. $(2009,51)$

Não obstante, a definição de Deleuze de um tempo 'fora dos eixos' e 'em estado puro' é inteiramente aplicável à representação urbana de Portugal nos filmes em questão aqui. De fato, esses filmes utilizam precisamente a localização do país no extremo oeste da Europa, isto é, na periferia da auto-atribuída modernidade europeia, de modo a configurá-lo como uma espécie de hiato espaço-temporal, ou um 'tempo em estado puro', que oferece um ponto de vista distanciado para a observação de fenômenos objetivos. Vistas sob tal perspectiva, as categorias de moderno e pós-moderno se tornam irrelevantes, pois não constituem indicadores confiáveis da existência de política progressista. Quero crer que, se tais indicadores existem, será mais fácil encontrá-los nas características estéticas do filme do que no momento histórico da sua produção. Defendo a hipótese de que dois desses possíveis indicadores são a stasis reflexiva e a inversão de escala, como descrevi acima a respeito dos três filmes em questão.

Cabe acrescentar que, uma vez descartadas as categorias de cinema moderno e pós-moderno enquanto indicadores políticos e/ou artísticos, a categoria de cinema ‘clássico' também deverá ser posta 
em questão. Segundo a famosa definição de Bordwell, Staiger e Thompson, o estilo 'clássico' no cinema deriva das regras narrativas e de mise-en-scène consagradas pelas produções de Hollywood desde a origem até os anos 60 (2002). No entanto, a identificação de Bazin e Deleuze do modelo clássico com o cinema de montagem e de ação significa que praticamente qualquer filme que não se enquadre no estilo realista fenomenológico, para o primeiro, e na imagem-tempo, para o segundo, poderia, em princípio, ser considerado 'clássico'. Em tempos mais recentes, ensaios como o de Miriam Hansen, "The mass production of the senses: classical cinema as vernacular modernism" (2000), têm proposto organizações mais maleáveis da história do cinema. Entre outros argumentos, Hansen recorre ao potencial autoreflexivo dos antigos clássicos hollywoodianos - por exemplo, a fisicalidade excessiva das comédias de pastelão (2000, 342-3) - para explicar como tais filmes poderiam ter desencadeado modernismos vernaculares em outros lugares do mundo. Mais recentemente, Laura Mulvey formulou hipótese semelhante, com base no potencial autoreflexivo do recurso de rear projection, que, em suas palavras, "contrabandeia algo do modernismo" para dentro da narrativa clássica (2011, 208).

Minha própria posição é de que a insistência no tríptico clássico-moderno-pós-moderno traz em si a expectativa latente de que uma linha evolutiva possa confirmar a teleologia da história que privilegia o novo sobre o velho. Mais especificamente, parece-me que todas essas teorias sofisticadas, incluindo o realismo de Bazin, a imagem-tempo de Deleuze, o modernismo vernacular de Hansen e as visões 'neo-modernas' relativas aos novos cinemas, estão se referindo a momentos ou elementos que representam ou produzem uma pausa auto-reflexiva no tempo narrativo, abrindo espaço para a participação espectatorial como evidência das credenciais artísticas e políticas de um filme. A contribuição específica deste meu trabalho pretende ser a ideia da inversão de escala como complemento natural da stasis reflexiva, na medida em que confere ao filme um ponto de vista distanciado e autocrítico. Ambos os recursos me parecem indicadores mais confiáveis do valor de um filme do que a teleologia histórica. Como espero ter demonstrado, as cidades portuguesas, em sua representação cinematográfica como hiato espaço-temporal favorecendo a observação distanciada e a reflexividade, efetivamente dispensam categorias baseadas em marcos cronológicos e periodizações evolucionistas. É o trabalho do tempo e do espaço nos próprios filmes que nos permite avaliar seu lugar na história. 


\section{BIBLIOGRAFIA}

Andrew, Dudley. 2010. "Ghost Towns." In Cinema at the City's Edge: Film and Urban Networks in East Asia, ed. Yomi Braester e James Tweedie, 37-47. Hong Kong: Hong Kong University Press.

Araujo, Marcelo Carrard. 2002. "Daniela Thomas." In O Cinema da Retomada: Depoimentos de 90 cineastas dos anos 90, ed. Lúcia Nagib, 482-6. São Paulo: Editora 34.

Benjamin, Walter. 1999. Illuminations. Organização e introdução de Hannah Arendt, traduzido por Harry Zorn. Londres: Pimlico.

Bordwell, David, Janet Staiger e Kristin Thompson. 2002. The Classical Hollywood Cinema: Film Style \& Mode of Production to 1960. Abingdon: Routledge.

Boujout, Michel. 1986. Wim Wenders. Paris: Edilig.

Castelo Branco, Camilo. 2010. Mistérios de Lisboa. Lisboa: Relógio D’Água.

Deleuze, Gilles. 2005a. Cinema 1: Movement-Image. Nova York/Londres: Continuum.

Deleuze, Gilles. 2005b. Cinema 2: Time-Image. Nova York/Londres: Continuum.

Doane, Mary Ann. 2009. "Scale and the Negotiation of 'Real' and 'Unreal' Space in the Cinema." In Realism and the Audiovisual Media, org. Lúcia Nagib e Cecília Mello, 63-81. Basingstoke: Palgrave.

Habermas, Jürgen e Seyla Ben-Habib. 1981. "Modernity versus Postmodernity." New German Critique 22, Special Issue on Modernism: 3-14.

Hansen, Miriam. 2000. "The mass production of the senses: classical cinema as vernacular modernism.” In Reinventing Film Studies, org. Christine Gledhill e Linda Williams, 332-51. Londres: Arnold.

Hell, Julia e Andreas Schönle. 2010. "Introduction.” In Ruins of Modernity, org. Julia Hell e Andreas Schönle, 1-14. Durham, NC: Duke University Press.

Lyotard, Jean François. 1986. The Postmodern Condition: A Report on Knowledge. Tradução de Geoff Bennington e Brian Massumi. Manchester: Manchester University Press.

Mulvey, Laura. 2011. "Rear-Projection and the Paradoxes of Hollywood Realism." In Theorizing World Cinema, org. Lúcia Nagib, Chris Perriam e Rajinder Dudrah, 207-220. Londres/Nova York: I.B. Tauris. 
Nagib, Lúcia. 2010. "Back to the Margins in Search of the Core: Foreign Land's Geography of Exclusion." In Cinema at the Periphery, org. Dina Iordanova, David Martin-Jones e Belén Vidal, 190210. Detroit: Wayne University Press.

Orr, John. 2000. "Introduction." In Post-war Cinema and Modernity: A Film Reader, org. John Orr e Olga Taxidou, 5-12. Edimburgo: Edinburgh University Press.

Rancière, Jacques. 2009. Aesthetics and its Discontents. Translated by Steven Corcoran. Malden, MA: Polity.

Singer, Ben. 2001. Melodrama and Modernity: Early Sensational Cinema and Its Contexts. Nova York: Columbia University Press.

Thomas, Daniela, Marcos Bernstein e Walter Salles. 1996. Terra Estrangeira. Rio de Janeiro: Rocco.

von Moltke, Johannes. 2010. "Ruin Cinema." In Ruins of Modernity, org. Julia Hell e Andreas Schönle, 395-417. Durham, NC: Duke University Press.

Wenders, Wim. 2001. On Film: Essays and Conversations. Londres: Faber and Faber. 